Biology | Dr Matthias Wilm

\title{
Unravelling the properties of membrane proteins
}

30 years ago Matthias Wilm laid the scientific foundation today facilitates the synthesis and self-assembly of lipid membranes with protein granting insight into a complexity that has evolve over a million years of

membrane protein evolution. environmental context, the use radical changes to how scientists solve problems an carry out investigations into
the lipid membrane's surprising properties. of molecular beams promises

he cell is the building block of
nearly all forms of life. Its outer
shell is a lipid membrane. These lipid membranes carry out a variety of cell-organism communication, depending on which proteins they contain. Bacteria tend to have little variety of membrane proteins and humans have many-almost a
third of all human proteins are membrane third of all Tuman proteins are membran proteins. The biological evolution of some impressive properties. The hum retina can detect single photons in dark environments with the help of membran proteins. Membrane proteins in plants are largely responsible for photosynthesis and ultimately the production of oxygen. Molecular recognition of hostile bacteria by membrane proteins is a vital part of the human immune system's defences against disease. For all these reasons it is important to study membrane proteins and replicate the above processes in detail within a technical environment. This, however, is not always easy due to absence of adequate methodology for the synthesis of lipid qumbras for proteins in reas

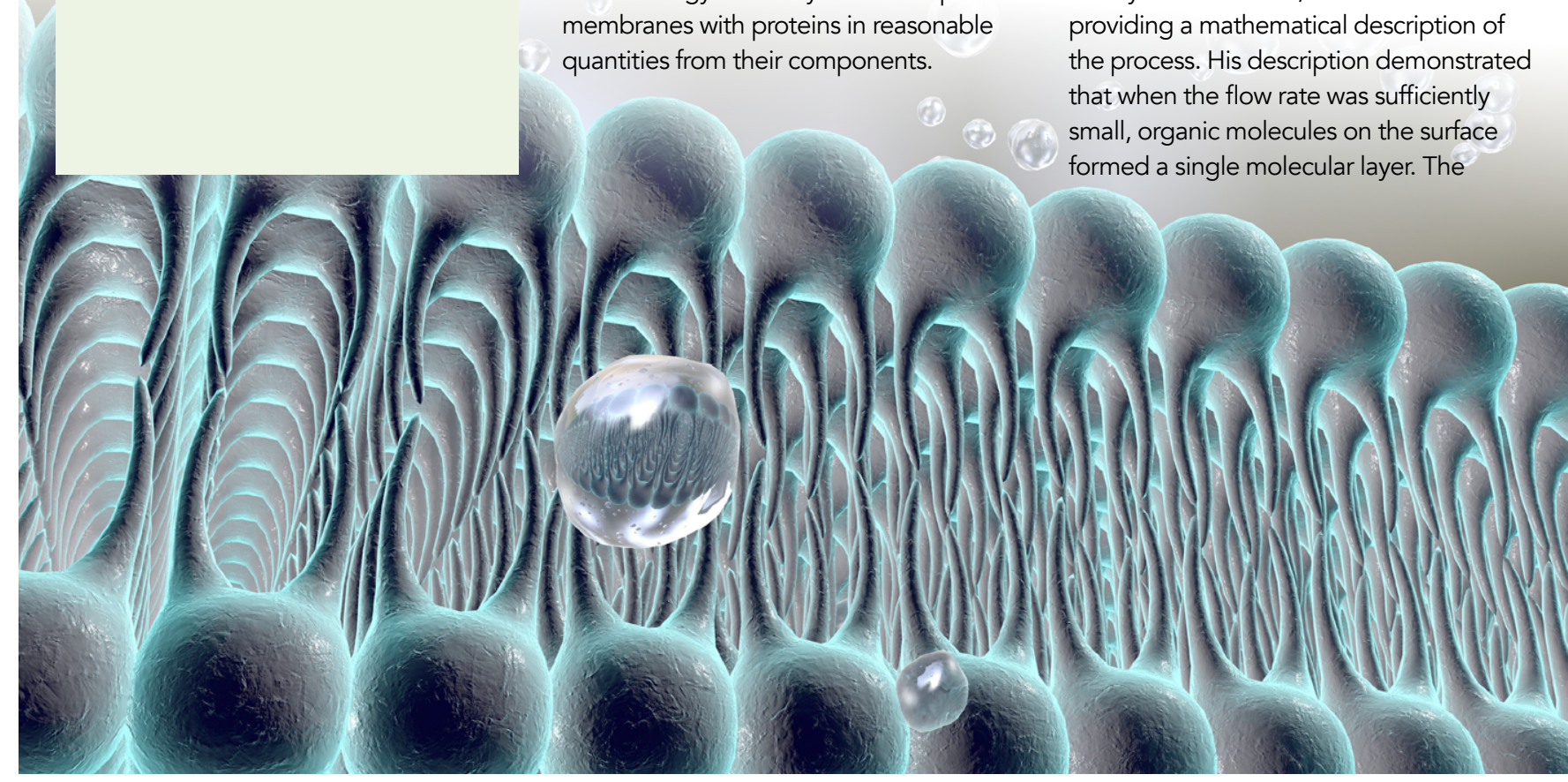

droplets produced by this electrospray device were so small, they contained an At the time, this gave weight to the theory that the nano electrospray could produce stable ions of unlimited mass when directed towards the vacuum of mass spectrometer. The transfer of these tiny droplets from atmosphere to vacuum causes the solvent to evaporate and the organic molecules are cooled down, much like when the alcohol in perfume evaporates on skin, and by this stabilised.

This solved the problems associated with vaporising and ionising proteins and peptides. In this case by passing the analyte through a needle kept at high electrical potential, the solution dis into a mist of small highly charged The droplets eap pror a rocess of field desorption or residu solvents protein molecules into the gas phase.

In recent years, nano-electrospray has been used to generate from gas phase and under atmospheric conditions, at the molecular level, designed layers that allow self-assembly into lipid membranes including proteins. This approach is very similar to the synthesis of crystalline structures of small molecules by molecular beams in vacuum called molecular beam epitaxy. A prominent example of the latter are graphene layers, single layers of carbon crystals For both momising electronic properties. he lipid membranes gaphene and methods to manufacture them on a larger scale are in high demand The nano-electrospray based approach seems to have solved this problem for the biological membranes. As a molecular beam device for all proteins, it makes no explicit use of any particular protein property and is generally applicable opening up many possibilities. This allows the study of membrane proteins in both (wintic and controlled in vitro systems (within the test tube). As Professor Wil explains: "The promise is a scaleable kind of soft opens the doors to a new kind of soft-matter technology that gives access to membrane protein properties fose evith thok place overnillons of years. I think these nano-electrospray
Membrane Protein Purification DETERGENT भi?:

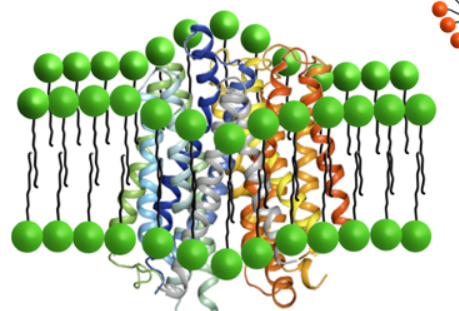

PROTEIN

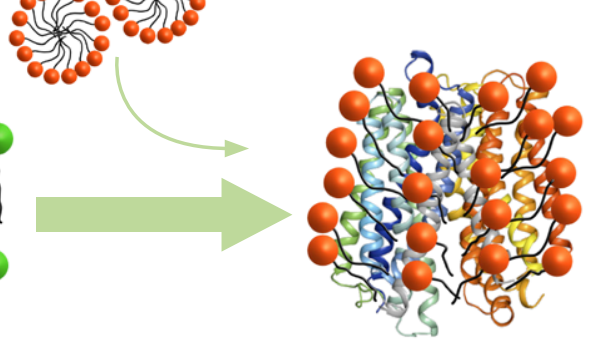

DETERGENT SOLUBILISED PROTEIN

列 the membranes. For this purpose detergents are added to cells. Detergents are molecules that envel op
membrane proteins and take them out of the membranes without harming their three-dimensional structure, in a similar way to the action of biochemists' "graphene". As much as the of the membrane proteins. Since it is ver physisists modity the electronic properties difficult, time-and material-consuming elements other than carbon, the currently the method of choice: cry(i) properties of these arifial memical by incorporating different proteins."

SELF-ASSEMBLING BIOACTIVE MEMBRANES: PROBLEMS electron microscopy. Membrane patches containing the proteins are rapidly frozen and electron-microscopic images are With enough pictures a computer programme can reconstruct the threedimensional shape of the protein One use of self-assembled membranes molecule. This is similar to the 3D

The nano-electrospray generates membranes that are huge, containing thousands of proteins.

containing proteins is the study of the three dimensional atomic structure a computer after laser scanning only that of the proteins. Tradtionally, there are the molecule is much smaller and more two of them requiring $2 \mathrm{D}$ or $3 \mathrm{D}$ crystals

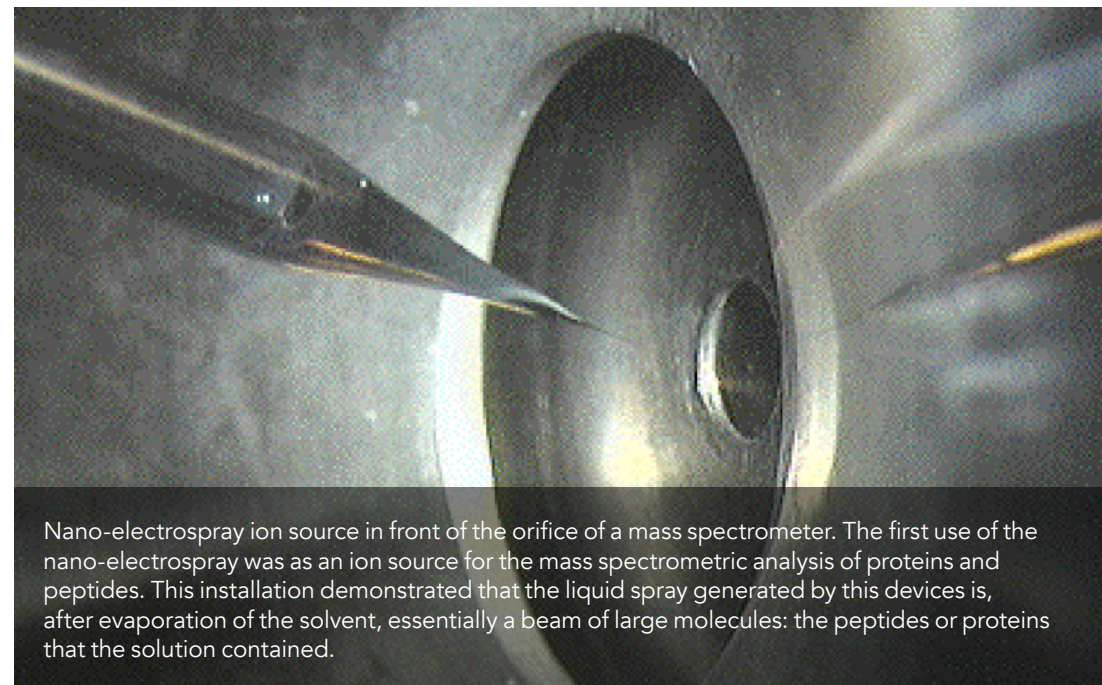


Membrane Reconstitution
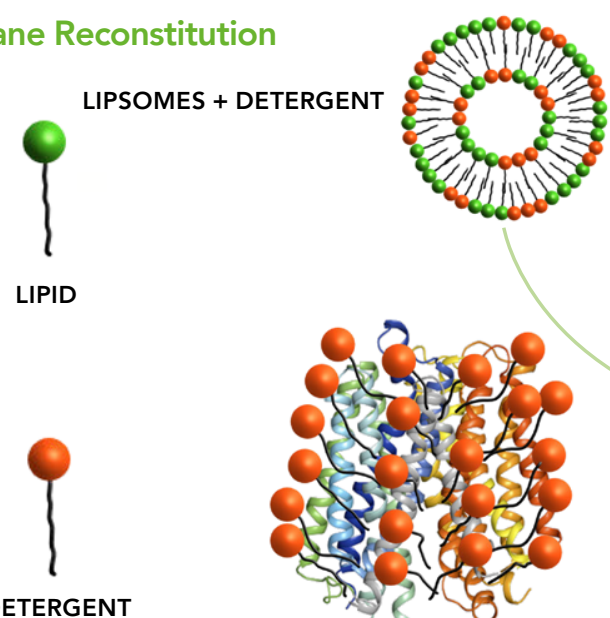

SM-2 BIOBEADS

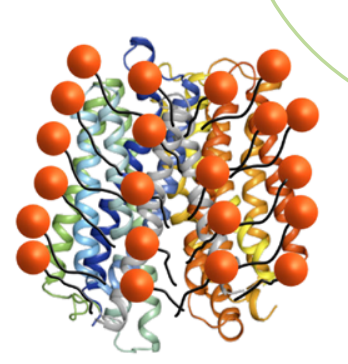

DETERGENT SOLUBILISED
PROTEIN
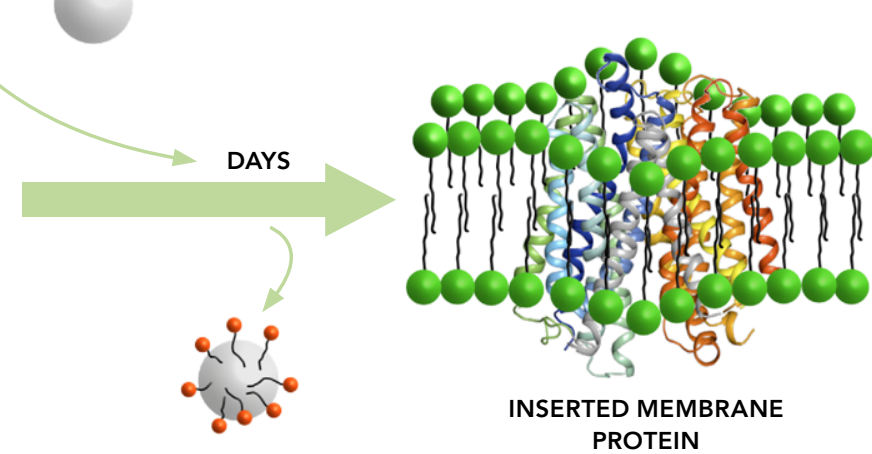

$\underset{\substack{\text { INSERTED MEMBRANE } \\ \text { PROTEIN }}}{ }$

Membrane reconstitution from purfified protein solution. After extraction and enrichment, membrane proteins have to be brought back into a lipid membrane

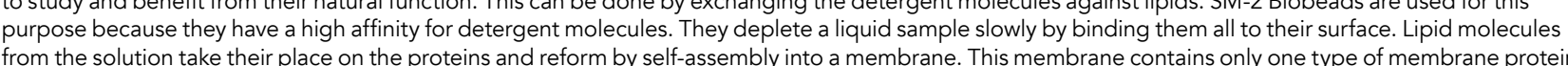

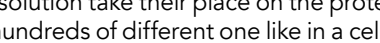

With low-flow electrospray, droplets can be produced that are so small they contain only one protein moleculle.

reconstruction. The nano-electrospray generated membranes are huge, and contain thousands of proteins. Hence, a single preparation can be sufficient to acquire enough images. This can currenty only be achieved with dozens if not hundreds of individual preparations.

The function of membrane proteins can be studied in synthetic, controlled in is scalsable, making these metring available for sensor development employing integral receptor membra proteins. The current technique used for

this purpose is called tethered bimolecular lipid membranes (tBLMs). Here, a lipid layer is fixed to a solid support by coupling certain chemical structures within membrane proteins to a surface. With th method, it has been demonstrated that bilayers with a specific electrical resistance of more than $10{\mathrm{M} \Omega \mathrm{cm}^{2}}^{2}$ can be generated routinely. However, the receptor protein must contain chemical groups which can the restriction of its free mabilidy can in its function. All this is no longer required because the membrane can be generted without support on a liquid surface using

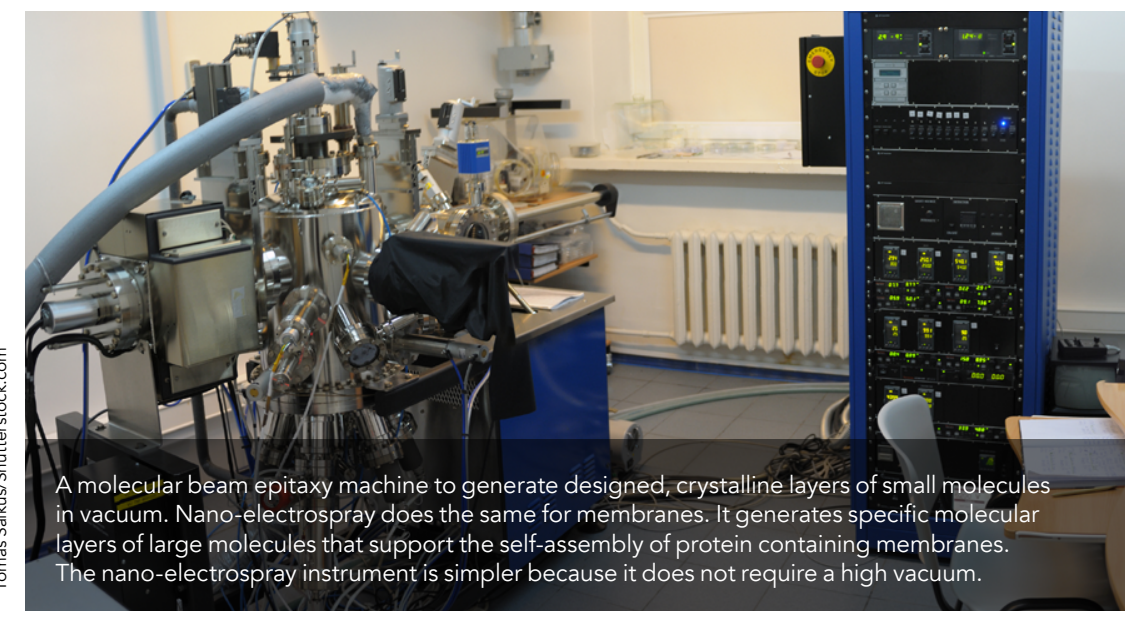

no-electrospray and then transferred in a more flexible way to a technical device, for instance by carrying it on a thin grid. without chemical fixation, in a similar way as leaves are fished out of an outdoor swimming pool in autumn.

The functionality of such lipid membranes is assessed by dedicated experiments. A lipid-like molecule called valinomyci binds potassium $\left(K^{+}\right)$ions and facilitates their transport across the lipid bilayer. This can be tested by simultaneously incorporating the $\mathrm{H}^{+}$channel protein M2 into the membrane. When $\mathrm{K}^{+}$ion cross the membrane at sites where flnomyon is present, $\mathrm{H}$ current hann $\mathrm{K}^{+}$ions affects the $\mathrm{H}^{+}$transport since both ions carry the same charge and withstand accumulation on the same site of the membrane.

This work is only a simple example that biological membranes constitute their own chemical environment. How much more can be achieved after we have gained free choice of the membrane through the nano-electrospray based meugh the nano-electrospray based Matthias Wynthesis? This is what of the arrival of a news when he speals echnology which takes atron of the properties of highly evolved membrane proteins.

\section{Behind the Research \\ - Dr Matthias Wilm}

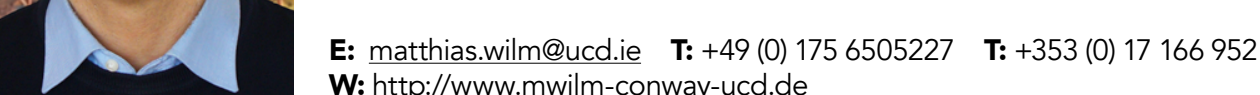

Research Objectives

Initially, Matthias Wilm studied the electrospray process and then applied it to the mass spectrometric analysis of biological samples. Today, he develops software to visualise and analyse mass spectrometric data and uses electrospray for the synthesis biological membranes.

\section{Detail}

Matthias Wilm, MD PhD, Professor for Bioanalytics

UCD Conway Institute of Biomolecular and Biomedical Research Room F098, University College Dublin Belfield, 4 Dublin, Ireland

Bio

Matthias Wilm studied Mathematics, Physics and Medicine at WWU, Münster,

\section{References}

Benninghoven, A., Hagenhoff, B. and Niehuis, E. (1993). Surface MS: probing real-world samples. Analytical Chemistry, 65(14), 630A-640A. https://pubs.acs.org/doi/10.1021/ ac00062a002

Mann, M. and Wilm, M. (1995). Electrospray mass pectrometry for protein characterization. Trends in Biochemical Sciences, 20(6), 219-224. https://www.cell.com/ trends/biochemical-sciences/fulltext/S0968-0004(00)89019-2

Wilm, M.S. and Mann, M. (1994). Electrospray and TaylorCone theory, Dole's beam of macromolecules at last? International Journal of Mass Spectrometry and lon Processes, article/pii/0168117694040249

Wilm, M. (2019). Synthesis of Extended, Self-Assembled Biological Membranes containing Membrane Proteins from Gas Phase, bioRxiv, https://doi.org/10.1101/661215

Wilm, M. (2019). Evidence for Membrane Complex Assembly in Nanoelectrospray Generated Lipid Bilayers, bioRxiv, https:// doi.org/10.1101/66123
Germany, before completing his Medical Funding Doctorate in 1991. He then completed his Science Fo
win Biology Laboratory (EMBL, Heidelberg). He completed his post doc at EMBL and 1998 . He Proteonics group leader Profer a 作

Collaborator

ProfWerner Kühlbrandt, Max Planck Director, Max Planck Institute of

\section{Personal Response}

\section{What was the most difficult aspect of developing
this technology?}

III The most difficult aspect of this research was to where nobody elser believed that my work made any sense. For this you must have a strong sense of independence and self-confidence.

More practically, there were two major hurdles. The first, lin tod the nan to complete all the calculations which finally showed that with low-flow electrospray, droplets can be produced that are so small they contain only one protein molecule. This essentially converts the stream of droplets into a beam of molecules.

The second hurdle was to find the exact conditions under would self-assemble. The challenge was to integrate the proteins. This was essentially an empirical process and required hundreds of experiments. 